\title{
What are the causes of excessive daytime sleepiness in patients with sleep-disordered breathing?
}

To the Editors:

Recently, the European Respiratory Journal published a study by MEDIANO et al. [1] on the determinants of excessive daytime sleepiness (EDS) in obstructive sleep apnoea (OSA) patients. The study did not find differences in body mass index (BMI), age or apnoea/hypopnoea index (AHI) between OSA patients with and without EDS, but found significantly more pronounced nocturnal hypoxaemia in patients with EDS, and concluded that nocturnal oxygen desaturation is involved in the pathogenesis of EDS. In his letter commenting on this work, BАНАМмАм [2] pointed out that the possible role of obesity hypoventilation syndrome (OHS), a known cause of EDS, was not ruled out by MEDIANO et al. [1]. OHS patients have the same AHI of pure OSA patients matched by age and BMI, but are characterised by apnoeas of longer duration and more severe nocturnal hypoxaemia [3], like the EDS patients studied by MEDIANO et al. [1]. In other words, BAHAMMAM [2] suggests that the lower nocturnal oxygen saturation and the associated daytime somnolence observed by MEDIANO et al. [1] in the EDS group might be due to OHS. Thus, BAHAMMAM [2] also concludes that low nocturnal blood oxygen saturation has a fundamental role in EDS, whether or not it is related to OHS.

However, data we have collected from patients with sleepdisordered breathing support the hypothesis that EDS is not always associated with low nocturnal blood oxygen saturation in sleep-related breathing disorders, and that other factors are involved. We have recently demonstrated an association between EDS and impaired autonomic cardiac modulation, suggesting that autonomic arousals may be an additional cause of EDS [4]. Autonomic arousals involve brainstem neurons controlling both sleep/vigilance and cardiovascular regulation.

\begin{tabular}{lccc} 
TABLE 1 & $\begin{array}{c}\text { Comparison of patients without excessive } \\
\text { daytime sleepiness (EDS) and non-obese } \\
\text { patients with EDS }\end{array}$ & p-value \\
& \multicolumn{3}{c}{ EDS } \\
\cline { 2 - 3 } & With & Without & \\
\hline & 23 & 13 & 0.89 \\
Subjects $\mathbf{n}$ & $29.2 \pm 25.8$ & $30.5 \pm 27.3$ & 0.86 \\
AHI $\mathbf{n} \cdot \mathbf{h}^{-1}$ & $25.0 \pm 7.6$ & $25.5 \pm 7.3$ & 0.92 \\
Apnoea duration s & $90.0 \pm 5.4$ & $90.2 \pm 3.8$ & $<0.03$ \\
Sa, $\mathbf{O}_{\mathbf{2}}$ min \% & $6.1 \pm 4.2$ & $3.3 \pm 2.3$ & \\
LF/HF power ratio & & & \\
\hline
\end{tabular}

Data presented as mean $\pm \mathrm{SD}$. All p-values were calculated using an unpaired ttest, after log transformation of the low- to high-frequency (LF/HF) power ratio data. AHI: apnoea/hypopnoea index; $\mathrm{Sa}_{1} \mathrm{O}_{2}$ : arterial oxygen saturation. Data presented are based on a subset of data analysed in [4].
They might not produce detectable electroencephalogram (EEG) changes but are responsible for changes in cardiac autonomic regulation, as reflected by baroreflex sensitivity [5] and heart rate variability indices [6]. To test our hypothesis, we studied sleep-disordered breathing patients with a wide spectrum of disease severity, from simple snoring to OSA [4]. We found that EDS is actually associated with reduced baroreflex sensitivity occurring at night and with an increased ratio of the low- to high-frequency (LF/HF) heart rate power, the latter of which is an indirect index of sympatho/vagal balance [6]. Baroreflex sensitivity and the LF/HF power ratio were inversely correlated, and only the LF/HF power ratio was found to be a statistically independent predictor of daytime somnolence at multivariate analysis. Compared to the population studied by MEDIANO et al. [1], overall, our patients were characterised by lower BMI (29 versus $32 \mathrm{~kg} \cdot \mathrm{m}^{-2}$ ) and AHI (35 versus $61 \mathrm{n} \cdot \mathrm{h}^{-1}$ ). Like MEDIANO et al. [1], we did not find differences in age, BMI and AHI between patients with and without EDS. Nor, however, did we find the significant differences between nonEDS and EDS patients in apnoea durations and in the minimum value of arterial oxygen saturation at night that MEDIANO et al. [1] reported in their study.

The discrepancy between our study and that of MEDIANO et al. [1] could be related to a lower prevalence of OHS in our EDS group. Although we too cannot completely exclude the presence of OHS in our study group, this is unlikely because the mean BMI was $<30 \mathrm{~kg} \cdot \mathrm{m}^{-2}$ and because analysis of daytime blood gases did not reveal hypercapnia. To better assess this issue, and to completely rule out the presence of OHS in our EDS patients, we have reanalysed our data after excluding all the obese patients, i.e. all subjects with a BMI $\geqslant 30 \mathrm{~kg} \cdot \mathrm{m}^{-2}$, in the EDS group. The mean \pm SD BMI of this selected subgroup of our EDS patients decreased to $26.6 \pm 2.2 \mathrm{~kg} \cdot \mathrm{m}^{-2}$. However, in spite of such careful exclusion of OHS, a significantly higher LF/HF power ratio was still found as compared to that in non-EDS patients, while AHI, apnoea duration and the minimum nocturnal oxygen saturation were practically the same as in patients without EDS (table 1).

In conclusion, the study of MONTANO et al. [1] and our study [4] together suggest that at least two independent factors are associated with the pathogenesis of excessive daytime sleepiness in sleep-disordered breathing patients. One is a low nocturnal oxygen saturation, probably caused by obesity hypoventilation syndrome, as BAHAMMAM [2] pointed out; another is an enhanced sympathetic cardiac modulation at night, probably caused by repeated nocturnal autonomic arousals, as we have hypothesised [4].

\section{P. Castiglioni*, C. Lombardi ${ }^{\#}$, M. Di Rienzo*, E. Lugaresi", P. Montagna ", P. Cortelli ${ }^{\top}$ and G. Parati ${ }^{\#}$}

*Biomedical Technology Dept, Santa Maria Nascente Research Hospital, Don Gnocchi Foundation, and "Cardiology, S. Luca 
Research Hospital, Italian Institute of Auxology, Milan, and Center for Sleep Disorders, Dept of Neurological Sciences, University of Bologna, Bologna, Italy.

\section{STATEMENT OF INTEREST}

None declared.

\section{REFERENCES}

1 Mediano O, Barceló A, de la Peña M, Gozal D, Agustí A, Barbé F. Daytime sleepiness and polysomnographic variables in sleep apnoea patients. Eur Respir J 2007; 30: 110-113.

2 Bahammam A. Excessive daytime sleepiness in patients with sleep-disordered breathing. Eur Respir J 2008; 31: 685-686.
3 Bahammam A, Syed S, Al-Mughairy A. Sleep-related breathing disorders in obese patients presenting with acute respiratory failure. Respir Med 2005; 99: 718-725.

4 Lombardi C, Parati G, Cortelli P, et al. Daytime sleepiness and neural cardiac modulation in sleep-related breathing disorders. J Sleep Res 2008; [Epub ahead of print PMID: 18503513]

5 Bonsignore MR, Parati G, Insalaco G, et al. Baroreflex control of heart rate during sleep in severe obstructive sleep apnoea: effects of acute CPAP. Eur Respir J 2006; 27: 128-135.

6 Heart rate variability. Standards of measurement, physiological interpretation, and clinical use. Task Force of the European Society of Cardiology and the North American Society of Pacing and Electrophysiology. Eur Heart J 1996; 17: 354-381.

DOI: $10.1183 / 09031936.00043308$

\section{Lung volume measurements}

\section{To the Editor:}

I read with interest the impressive paper by CAzzolA et al. [1] in a recent issue of the European Respiratory Journal.

However, I felt somewhat uneasy reading the recommendations on lung volume measurements, i.e. closing circuit dilution methods and body plethysmography.

CAzzola et al. [1] state "either method can be used... However they are not interchangeable, since moderate-to-severe airflow obstruction dilution methods tend to underestimate and body plethysmography tends to overestimate TLC".

Therefore, according to CAzzOLA et al. [1], in moderate-to-severe airflow obstruction no method is accurate. What, therefore, is the choice? To accept underestimation of lung volume since the dilution methods are "less expensive and less demanding"? Or, in spite of the overestimation of total lung capacity, to use a body plethysmograph, since it is "time saving"?

In fact, dilution methods do underestimate lung volume in moderate-to-severe airflow obstruction [2-4]. The more severe the airflow obstruction, the larger the underestimation [4].

Body plethysmography might indeed overestimate total lung capacity in airflow obstruction if incorrectly measured $[5,6]$. However, the plethysmographic method is accurate even in moderate and severe airflow obstruction by breathing or panting at $<1 \mathrm{~Hz}[7,8]$.

\section{Stanescu}

Medical School, Catholic University of Louvain, Brussels, Belgium.

\section{STATEMENT OF INTEREST}

None declared.

\section{REFERENCES}

1 Cazzola M, MacNee W, Martinez FJ, et al. Outcomes for COPD pharmacological trials: from lung function to biomarkers. Eur Respir J 2008; 31: 416-469.

2 Herzog H, Keller R, Amrein R, Matthys H, Joos J. Patterns of correlation of pulmonary function values determined by spirography and body plethysmography. In: DuBois $\mathrm{AB}$, Van de Woestijne KP, eds. Body Plethysmography. Basel, Karger, 1969; pp. 205-214.

3 Mikus JP, Robins AG, Burke GW, et al. Comparison of five methods for determination of FRC and TLC in 100 persons: appendix 6 of the American Thoracic Society Epidemiology Standardization Project. Am Rev Respir Dis 1978; 118: 92-104.

4 Rodenstein DO, Stănescu DC. Reassessment of lung volume measurement by helium dilution and by body plethysmography in chronic air-flow obstruction. Am Rev Respir Dis 1982; 126: 1040-1044.

5 Stănescu DC, Rodenstein DO, Cauberghs M, Van de Woestijne KP. Failure of body plethysmography in bronchial asthma. J Appl Physiol 1982; 52: 939-948.

6 Rodenstein DO, Stănescu DC, Francis C. Demonstration of failure of body plethysmography in airway obstruction. $J$ Appl Physiol 1982; 52: 949-954.

7 Shore SA, Huk O, Mannix S, Martin JG. Effect of panting frequency on the plethysmographic determination of thoracic gas volume in chronic obstructive pulmonary disease. Am Rev Respir Dis 1983; 128: 54-59.

8 Rodenstein DO, Stănescu DC. Frequency dependence of plethysmographic volume in healthy and asthmatic subjects. J Appl Physiol 1983; 54: 159-165. 